\title{
The Potential of Rhamnolipid as Biofungicide against Rigidoporus microporus Isolated from Rubber Tree (Hevea brasiliensis)
}

\author{
Shaikh Mohd Hizami Shaikh Abd Hadi ${ }^{1,2}$, Mohd Shafiq Nasir ${ }^{1}$, Nur Asshifa \\ Md Noh ${ }^{1}$, Ahmad Ramli Mohd Yahya ${ }^{1}$ and Nik Mohd Izham Mohamed Nor ${ }^{1 *}$ \\ ${ }^{1}$ School of Biological Sciences, Universiti Sains Malaysia, 11800 USM, Pulau Pinang, Malaysia \\ ${ }^{2}$ Northern Regional Office of Malaysian Rubber Board, Lot. PT. 117753, Jalan Sultan Azlan Shah Utara, \\ 31400 Ipoh, Perak, Malaysia
}

\begin{abstract}
Rigidoporus microporus is the main causal of white root disease (WRD) in rubber trees (Hevea brasiliensis). The present study investigates the use of rhamnolipid, a biosurfactant produced by Pseudomonas aeruginosa USM-AR2 against $R$. microporus. In vitro doseresponses towards rhamnolipid were determined on different isolates of $R$. microporus using the poisoned food technique (PFT). Inhibition of mycelial growth was found to be dose-dependent, with the highest inhibition of $76.74 \%$ at $200 \mathrm{ppm}$ (pH 6.29) on SEG isolate. On the contrary, the lowest concentration of rhamnolipid applied at $10 \mathrm{ppm}(\mathrm{pH}$ 5.97) had effectively inhibited the growth of RL 19 to $34.36 \%$. AM isolate was assumed to be the most aggressive pathogen due to the lowest inhibition recorded on all rhamnolipid concentrations tested. At the same time, RL 19 was the least aggressive pathogen compared to the other R. microporus isolates. The rhamnolipid concentrations (ppm), which reduced mycelial growth at $50 \%\left(\mathrm{EC}_{50}\right)$, were recorded at $17.82 \mathrm{ppm}$ for $\mathrm{AM}$ isolate, $12.52 \mathrm{ppm}$ for RL 26, and $11.80 \mathrm{ppm}$ for RL 19 isolate. This result indicated that rhamnolipid concentrations to inhibit $50 \%$ of mycelial growth might vary based on the aggressiveness and the virulence levels of different $R$. microporus isolates. It was found that $\mathrm{pH}$ changes

ARTICLE INFO

Article history:

Received: 07 October 2021

Accepted: 13 December 2021

Published: 10 February 2022

DOI: https://doi.org/10.47836/pjtas.45.1.17

$\overline{\text { E-mail addresses: }}$

hizami@student.usm.my (Shaikh Mohd Hizami Shaikh Abd Hadi) mohdshafiqbinnasir@student.usm.my (Mohd Shafiq Nasir) after incorporating rhamnolipid into the PDA were not the main factor affecting the inhibition of $R$. microporus isolates. It is obvious that rhamnolipid had an inhibitory effect on fungal growth in vitro. It is the first report on rhamnolipid that has been shown to control $R$. microporus potentially.
\end{abstract}

nurasshifa@usm.my (Nur Asshifa Md Noh)

armyahya@usm.my (Ahmad Ramli Mohd Yahya)

nikizham@usm.my (Nik Mohd Izham Mohamed Nor)

* Corresponding author
Keywords: $\mathrm{EC}_{50}$, inhibition, isolate, in-vitro 


\section{INTRODUCTION}

White root disease, caused by the pathogenic fungus Rigidoporus microporus, is the most destructive root disease of Hevea brasiliensis Muell. Arg. worldwide (Oghenekaro et al., 2016). Rubber industries worldwide have been facing significant reductions in economic returns due to this disease since the infection kills rubber trees irrespective of age (Soytong \& Kaewchai, 2014). Hevea brasiliensis, regardless of clone and age, are susceptible to white root disease (Farhana et al., 2017). This disease occurs in young rubber plantations, virgin jungles, and replanted areas. It has been determined to be more severe in young rubber plantations, especially after two years of planting (Prasetyo et al., 2009). In Malaysia, a survey of rubber diseases conducted by the Malaysian Rubber Board in 2012 revealed that the incidence of white root disease occurred in 10-15\% of Peninsular Malaysia, $20-30 \%$ of Sabah, and 9-20\% in Sarawak out of the total area of rubber plantations, which amounts to 1,065,630 hectares (Atan, 2015). Furthermore, white root disease has resulted in more tree losses than red or brown root disease, particularly between the first to fourth years after planting (Nicole \& Benhamou, 1991; Wattanasilakorn et al., 2017). The application of sulfur as one of the standard preventive methods of white root disease during the early stage of rubber cultivation, has been adopted widely in rubber growing countries (Ismail \& Azaldin, 1985; Rodesuchit et al., 2012; Satchuthananthavale \& Halangoda, 1971).
In addition, drenching with triazole group of fungicide, propiconazole was believed to be an effective method to control $R$. microporus as the procedure was easy and fast (Hashim \& Chew, 1997). Although effective, this fungicide has caused a variety of problems for natural environments, including a significant impact on soil microbial diversity and human health, as well as being quite expensive when it is required to be used consistently (Go et al., 2013; Jayasuriya \& Thennakoon, 2007; Ogbebor et al., 2015; Satapute \& Kaliwal, 2015). Moreover, the incidence of white root disease is still widespread, prompting immediate further investigation into safer sources of natural fungicides for the control of R. microporus. Monnier et al. (2020) mentioned that rhamnolipids (RLs) are natural glycolipids mainly produced by the bacteria Pseudomonas aeruginosa. The robust surface activity of dirhamnolipid could be related to antifungals produced by rhamnolipid that inhibit the growth modes of dimorphic fungi resulting in the disruption of the cell membrane spore (Sha \& Meng, 2016). Aside from the recognized antifungal properties, rhamnolipids have never been studied for antifungal activities against $R$. microporus. RLs have a hydrophobic tail containing one or two fatty acids attached to the carboxyl end of one or two rhaminose molecules (Charles Oluwaseun et al., 2017). A few studies have shown a significant impact of rhamnolipid treatments in controlling plant diseases (Borah et al., 2016). 
Pseudomonas aeruginosa USM-AR2, a hydrocarbon-utilizing bacterium, has been shown to secrete copious amounts of rhamnolipid when grown on waterimmiscible substrates (Md Noh et al., 2014; Noh et al., 2012). Rhamnolipid has been explored as a potential antifungal agent for environmental-friendly agricultural practice. The concern lies in the repeated use of fungicides, which are harmful to the environment and increase the chemical resistance in the target organisms. Should rhamnolipid supplementation prove to be a viable alternative treatment for $R$. microporus, further study must be carried out to identify its mode of action and explore its potential in curbing the spread of white root disease. Hence, the current study has been intended to examine the ability of rhamnolipid to suppress $R$. microporus in vitro and its subsequent use to control white root disease of rubber in vivo.

\section{MATERIALS AND METHODS}

\section{Source of Isolate}

In this study, five isolates of $R$. microporus obtained from the Integrated and Disease Management Unit, Malaysian Rubber Board were RL 18, RL 19, RL 26, SEG, and AM. The locations of where the isolates were collected are presented in Table 1.

Table 1

List of Rigidoporus microporus isolates used in this study

\begin{tabular}{cc}
\hline Isolate & Locality of Collection \\
\hline RL 18 & Sungai Buloh, Selangor \\
RL 19 & Seremban, Negeri Sembilan \\
RL 26 & Kota Tinggi, Johor \\
SEG & Segamat, Johor \\
AM & Ayer Molek, Melaka \\
\hline
\end{tabular}

\section{Production of Rhamnolipid}

Rhamnolipid production was performed by cultivating $P$. aeruginosa USM-AR2 via a submerged batch fermentation. Cultivation was done in a $3.6 \mathrm{~L}$ stirred tank bioreactor (Labfors 4, INFORS HT, Switzerland) with a $1.5 \mathrm{~L}$ working volume at room temperature $\left(27-30^{\circ} \mathrm{C}\right)$, agitated at 400 rpm aerated at an airflow rate of $0.5 \mathrm{vvm}$. The $\mathrm{pH}$ was left uncontrolled. A minimal salt medium (MSM) was used to cultivate $P$. aeruginosa USM-AR2 containing the ingredients as follows (per liter): sodium nitrate $\left(\mathrm{NaNO}_{3}\right) 8.25 \mathrm{~g} / \mathrm{L}$, magnesium sulfate heptahydrate $\left(\mathrm{MgSO}_{4} \cdot 7 \mathrm{H}_{2} \mathrm{O}\right) 0.75$ $\mathrm{g} / \mathrm{L}$, potassium chloride $(\mathrm{KCl}) 1.5 \mathrm{~g} / \mathrm{L}$, dipotassium hydrogen phosphate $\left(\mathrm{K}_{2} \mathrm{HPO}_{4}\right)$ $0.45 \mathrm{~g} / \mathrm{L}$, waste cooking oil 5\% (v/v). Seed culture was prepared in nutrient broth before inoculation into the production medium. A $2 \%(\mathrm{v} / \mathrm{v})$ cell suspension of a $24-\mathrm{h}$ culture $\left(\mathrm{OD}_{540}=2\right)$ was used as the inoculum.

\section{Rhamnolipid Recovery}

The fermentation broth was centrifuged (Hettich Zentrifugen, Universal-320R, Germany) at $8000 \times g$ for 20 minutes to separate the supernatant containing rhamnolipid from the cells. Subsequently, the supernatant was transferred into a 500 $\mathrm{ml}$ shake flask and added ethyl acetate at a 1:1 volume ratio. The supernatant-solvent mixture was shaken at $200 \mathrm{rpm}$ for 1 hour in an orbital shaker (Thermo Scientific, MaxQ4000, USA). It was subsequently transferred into a separating funnel, where it was left to stand overnight to form separate layers. The upper aqueous layer containing rhamnolipid 
was carefully transferred into a glass Petri dish and dried overnight in a fume hood chamber. Dried crude rhamnolipid was scraped from the surface of the glass Petri dish and stored at $4{ }^{\circ} \mathrm{C}$ for further use.

\section{Agar Preparation}

Different rhamnolipid concentrations were screened against $R$. microporus isolates while commercial triazole group fungicide, propiconazole was tested against the most aggressive isolate of $R$. microporus using poisoned food technique (PFT) (Balamurugan, 2014; Durgeshlal et al., 2019) with slight modification. Firstly, 3,000 ppm of propiconazole and rhamnolipid were prepared as a stock of treatments and autoclaved at $121^{\circ} \mathrm{C}, 1.05 \mathrm{~kg} /$ $\mathrm{cm}^{2}$ for 21 minutes. Then, a specific amount of propiconazole and rhamnolipid stocks was incorporated into autoclaved potato dextrose agar (PDA) to achieve the desired concentration of 10, 25, 50, 100, and 200 ppm. The Petri dishes were shaken gently and laterally to allow propiconazole and rhamnolipid to distribute evenly in the PDA medium. PDA without rhamnolipid served as a negative control, while PDA amended with propiconazole serves as a positive control. The $\mathrm{pH}$ values of the prepared medium were recorded using Delta $320 \mathrm{pH}$ meter (Mettler Toledo Instruments (Shanghai) Co. Ltd, China). The $\mathrm{pH}$ value of unamended PDA was recorded to be 6.0. Additionally, the $\mathrm{pH}$ values recorded for propiconazole and rhamnolipid ranged between 5.45 to 5.91 and 5.39 to 6.29 , respectively, with the different concentrations applied into amended PDA. Subsequently, the agar solutions were decanted into Petri dishes and left to set before being incubated for two days to ensure no contamination.

\section{Antifungal Activity Assay}

A five $\mathrm{mm}$ diametric mycelial plug of 7 days old culture of $R$. microporus was placed at the center of the Petri dishes. The Petri dishes were then sealed with parafilm (Pechiney, USA) and incubated at room temperature. Data on the radial colony diameter were recorded seven days after incubation or when the growth of the control treatment completely covered the Petri dishes. In addition, a colony radius on PDA for each rhamnolipid concentration was measured from the bottom side of the Petri dishes. The mycelium was observed in-situ under an Olympus CX41 light compound microscope (Olympus Optical Co. Ltd. Tokyo, Japan) with a magnification of $10 \mathrm{x}$ and images recorded using an XCAM-a camera (The Imaging Source GmbH, Germany). Percentage inhibition of radial growth (PIRG) was calculated using the following formula developed by Skidmore and Dickinson (1976):

$$
\begin{aligned}
& \text { PIRG }(\%)= \\
& \left(\frac{\text { fungal growth-control growth }}{\text { control growth }}\right) \times 100 \%
\end{aligned}
$$

\section{Experimental Design and Data Analysis}

The experiments were conducted in a completely randomized design (CRD) with three replications. An analysis of variance (ANOVA) was performed using SPSS ${ }^{\circledR}$ 
24.0 for the Windows program. Factorial ANOVA analyses and Duncan's multiple range test (DMRT) were used to detect significant differences between treatments, and differences were considered significant when $p \leq 0.05$. All data were expressed as mean \pm standard error. $\mathrm{EC}_{50}$ represents the concentration at which a rhamnolipid exerts half of its maximal response was analyzed using $\mathrm{EC}_{50}$ calculator software (AAT Bioquest Inc, n.d.).

\section{RESULTS AND DISCUSSION}

The ability of $P$. aeruginosa culture to produce rhamnolipid when grown on oil substrates has been widely reported (Ndlovu et al., 2017; Shi et al., 2021; Vanavil \& Seshagiri, 2018). In this study, $P$. aeruginosa USM-AR2 was grown in a medium supplemented with waste cooking oil. Many studies have shown waste cooking oil as a renewable and lowcost substrate for rhamnolipid production (Chen et al., 2018; Radzuan et al., 2017). Waste cooking oil contains palm oil and other nutrient-rich compounds primarily to support microbial growth. Palm oil in waste cooking oil consists of saturated and unsaturated fats, made up of triglycerides, diglycerides, monoglycerides, and free fatty acids.

After five days of fermentation, $P$. aeruginosa USM-AR2 produced the rhamnolipid concentration of $3.0 \mathrm{~g} / \mathrm{L}$. Rhamnolipid is a secondary metabolite characterized by its production during the stationary phase. Towards the end of fermentation, an increase in rhamnolipid production was observed after microbial growth had ceased (Md Noh et al., 2014). Rhamnolipid is an extracellular metabolite; hence, it is secreted into the culture broth. It was harvested and recovered from the culture supernatant. Subsequently, the crude rhamnolipid suspension was used to screen antifungal activity against $R$. microporus.

It was found that rhamnolipid could inhibit the growth of $R$. microporus (RL 19 isolate) to $34.36 \%$ at the lowest concentration of rhamnolipid (10 ppm) used. In comparison, the highest concentration (200 ppm) of rhamnolipid had inhibited $76.74 \%$ growth of SEG isolate of $R$. microporus (Table 2). In addition, three

Table 2

Mean inhibition of Rigidoporus microporus isolates at different rhamnolipid concentrations in amended PDA

\begin{tabular}{cccccc}
\hline \multirow{2}{*}{$\begin{array}{c}\text { Concentration of } \\
\text { rhamnolipid (ppm) }\end{array}$} & \multicolumn{5}{c}{ Percentage inhibition of radial growth (\%) } \\
\cline { 2 - 6 } & RL 18 & RL 19 & RL 26 & SEG & AM \\
\hline 0 & $0.00 \pm 0.00^{\mathrm{a}}$ & $0.00 \pm 0.00^{\mathrm{a}}$ & $0.00 \pm 0.00^{\mathrm{a}}$ & $0.00 \pm 0.00^{\mathrm{a}}$ & $0.00 \pm 0.00^{\mathrm{a}}$ \\
10 & $30.39 \pm 1.71^{\mathrm{b}}$ & $34.37 \pm 1.83^{\mathrm{b}}$ & $29.52 \pm 3.35^{\mathrm{b}}$ & $25.64 \pm 2.37^{\mathrm{b}}$ & $24.66 \pm 2.47^{\mathrm{b}}$ \\
25 & $57.06 \pm 0.34^{\mathrm{c}}$ & $56.51 \pm 0.99^{\mathrm{c}}$ & $55.02 \pm 1.12^{\mathrm{c}}$ & $57.26 \pm 0.25^{\mathrm{c}}$ & $47.26 \pm 3.89^{\mathrm{c}}$ \\
50 & $65.29 \pm 0.59^{\mathrm{d}}$ & $67.98 \pm 0.58^{\mathrm{d}}$ & $60.24 \pm 1.20^{\mathrm{d}}$ & $64.41 \pm 1.45^{\mathrm{d}}$ & $59.81 \pm 1.65^{\mathrm{d}}$ \\
100 & $69.22 \pm 1.09^{\mathrm{e}}$ & $71.53 \pm 1.00^{\mathrm{e}}$ & $64.66 \pm 0.20^{\mathrm{d}}$ & $69.98 \pm 0.34^{\mathrm{e}}$ & $64.38 \pm 0.68^{\mathrm{d}}$ \\
200 & $75.10 \pm 0.85^{\mathrm{f}}$ & $76.47 \pm 0.90^{\mathrm{f}}$ & $73.89 \pm 0.72^{\mathrm{e}}$ & $76.74 \pm 0.38^{\mathrm{f}}$ & $74.66 \pm 5.14^{\mathrm{e}}$ \\
\hline
\end{tabular}

Note. Data are means of three replicates \pm SE. Different letters within each column indicate significantly different values $(p \leq 0.05)$ according to Duncan's multiple range test (DMRT) 
isolates of $R$. microporus known as RL 19, RL 26, and AM collected from different locations in Peninsular Malaysia (Table 1) showed significant differences after exposure against rhamnolipid (Table 2 and Figure 1). Indeed, the effectiveness of rhamnolipid in promoting plant growth and controlling plant diseases has been discussed in many studies (Goswami et al., 2015; Jishma et al., 2021; Monnier et al., 2020).
The effectiveness of rhamnolipid in reducing the mycelial growth of the $R$. microporus depends highly on its concentration. It showed a significant difference among the total concentrations (ppm) applied compared to control (without rhamnolipid addition) (Figures 2 and 3 ). The results obtained were similar to Deepika et al. (2015), who claimed a significant reduction in tomato disease severity with the increased concentration of

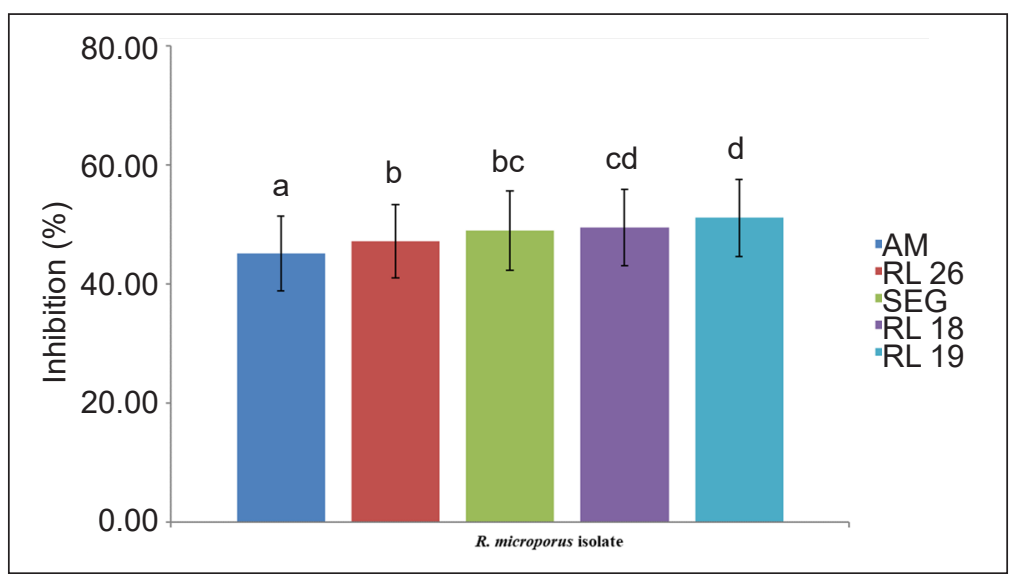

Figure 1. Inhibitory effect of rhamnolipid on mycelial growth of five (5) Rigidoporus microporus isolates on amended PDA with rhamnolipid. Error bars represent standard error (SE). Different letters indicate significantly different values at $p \leq 0.05$ according to Duncan's multiple range test (DMRT)

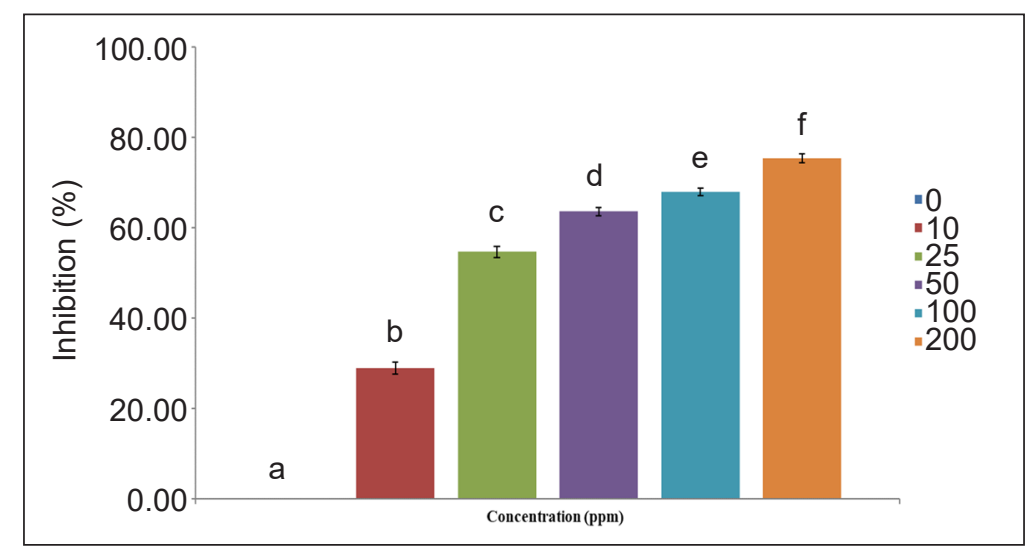

Figure 2. Inhibitory effect of different rhamnolipid concentrations on mycelial growth of Rigidoporus microporus isolates on PDA. Error bars represent standard error (SE). Different letters indicate significantly different values at $p \leq 0.05$ according to Duncan's multiple range test (DMRT) 


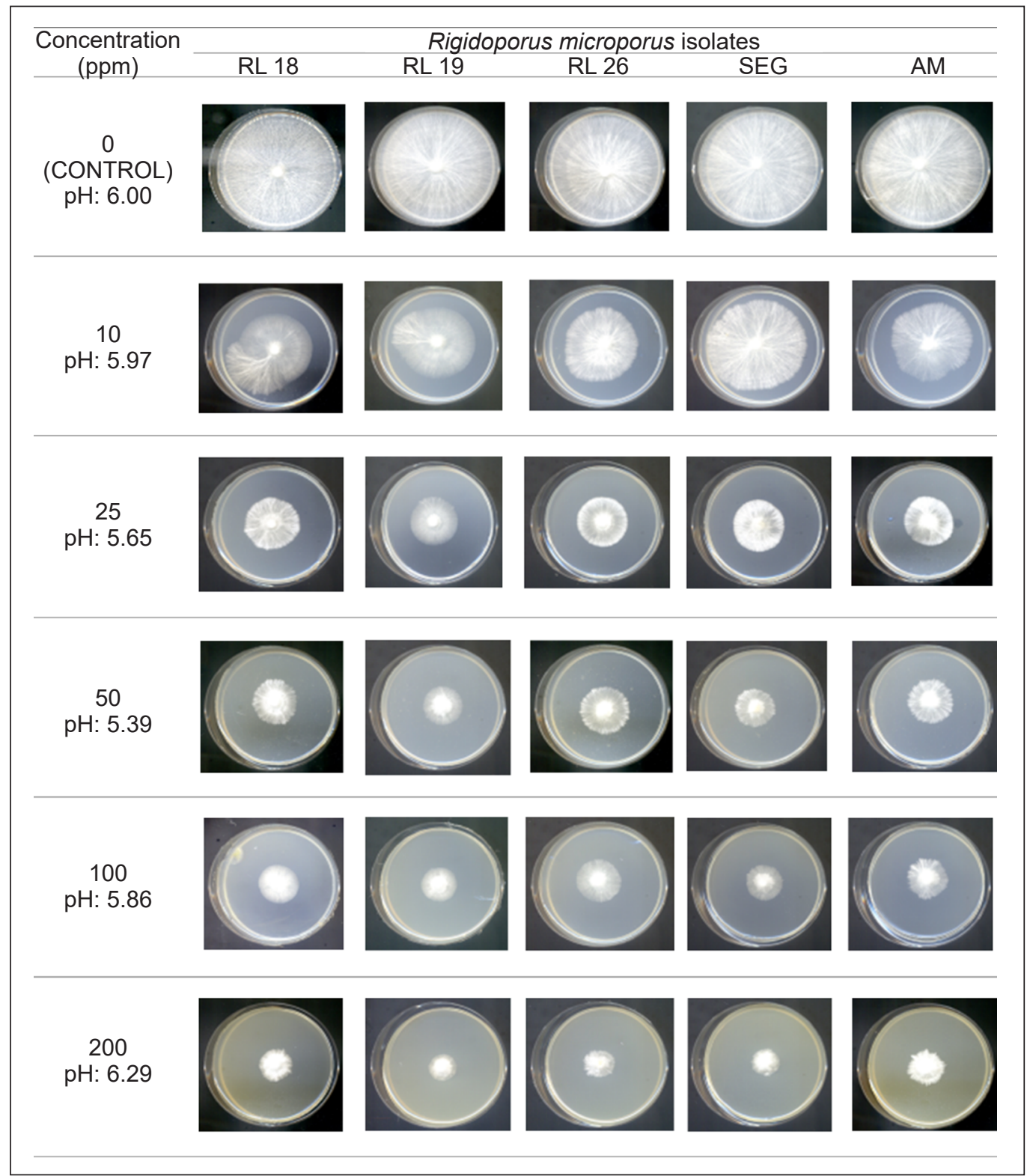

Figure 3. Cultures of Rigidoporus microporus in control and different concentrations of rhamnolipid incorporated into the PDA after 7 days of incubation

rhamnolipids used as treatment. Goswami found that the application of $60 \mu \mathrm{gml}^{-1}$ et al. (2015) mentioned that more than 60 rhamnolipids had inhibited the colony $\%$ reduction occurred on spore germination growth of Verticillium dahliae ATCC 7611 of Colletotrichum falcatum after exposure to the rhamnolipid at the concentration of up to $73 \%$.

In addition, rhamnolipid biosurfactant $50 \mathrm{\mu gml}^{-1}$. Simlarly, Sha and Meng (2016) was observed to be highly effective not 
only in completely inhibiting the eggplant disease severity caused by Fusariym oxysproum f. sp. melongenae (Fomg) was also environmentally friendly (Nalini \& Parthasarathi, 2018). On the contrary, Yan et al. (2014) revealed that rhamnolipid alone was not practical to control the growth of Alternaria alternata infection in cherry tomato fruit in vivo, but it was more efficient when combined with Rhodotorula glutinis. This finding was contended by Borah et al. (2016), who found the complete inhibition of stalk and ear rot disease in maize cv. PAC740 in a single application of rhamnolipid at $50 \mathrm{mg} \mathrm{l}^{-1}$.

On average, AM isolate exhibited the lowest inhibition rate (\%) compared to RL 19 isolate after being treated with different rhamnolipid concentrations (ppm). It is speculated that this is due to the different levels of virulence among isolates. Based on phylogenetic analysis of the $\beta$-tubulin gene region, it was discovered that $R$. microporus isolates collected from various areas in Malaysia using cultural and molecular characteristics had a distinct geographical origin among 27 local isolates (Andrew et al., 2021). Additionally, Siddiqui et al. (2017) claimed that AM isolate had been classified as an aggressive pathogen due to the expression of a higher number of proteins in AM-infected samples.

It was observed that the concentrations of rhamnolipid required to reduce mycelial growth at $50 \%\left(\mathrm{EC}_{50}\right)$ on RL 19, RL 26, and $\mathrm{AM}$ were recorded at $11.80 \mathrm{ppm}$, $12.52 \mathrm{ppm}$, and $17.81 \mathrm{ppm}$, respectively (Figure 4). The minimal concentration of

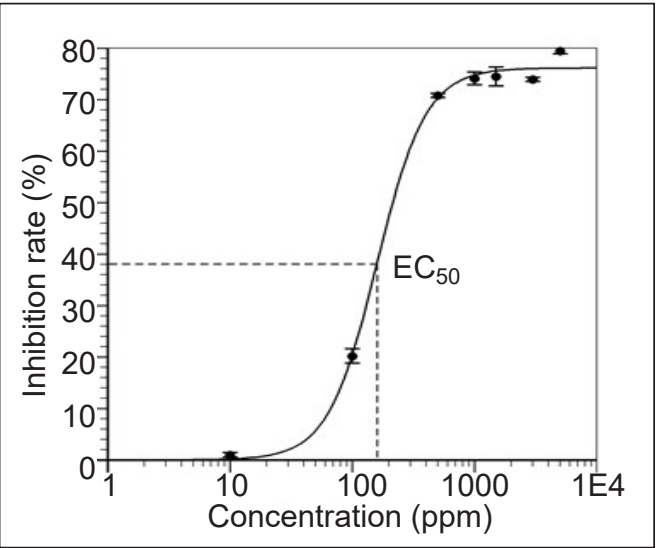

(a)

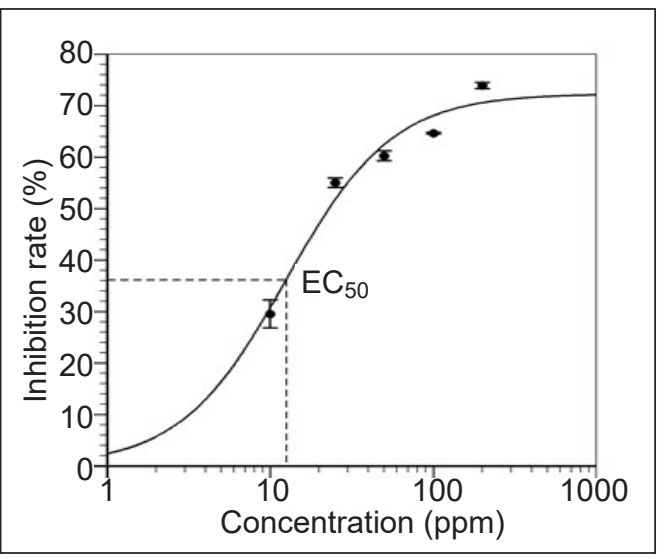

(b)

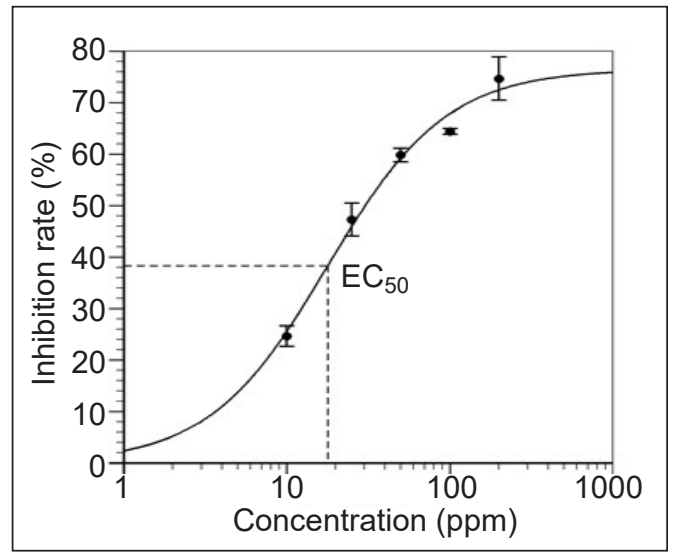

(c)

Figure 4. $\mathrm{EC}_{50}$ values of rhamnolipid concentration (ppm) on mycelium growth of three (3) isolates of Rigidoporus microporus on PDA. (a) $\mathrm{EC}_{50}$ of RL 19 $=11.80 \mathrm{ppm}$; (b) $\mathrm{EC}_{50}$ of RL $26=12.52 \mathrm{ppm}$; (c) $\mathrm{EC}_{50}$ of $\mathrm{AM}=17.81 \mathrm{ppm}$ 
rhamnolipid needed to reduce $50 \%$ of the $R$. microporus growth implies the efficacy of rhamnolipid as an alternative method to control the incidence of white root disease in rubber. In comparison to propiconazole, the efficacy of rhamnolipid requires a bit higher concentration to reduce $50 \%$ of fungal growth. The results were similar to the study on the effect of rhamnolipid towards A. alternata on cherry tomato fruit, where higher rhamnolipid concentration was required to control the pathogen compared to synthetic fungicides (Yan et al. 2014).

On the contrary, the application of the triazole group of fungicide, propiconazole, showed the highest inhibition growth of the $R$. microporus even at the minimal concentration of $10 \mathrm{ppm}(76.27 \%)$ (Table $3)$. Although effective in inhibiting the $R$. microporus growth, propiconazole could be detrimental to the environment and human health. Knebel et al. (2018) as well as Satapute and Kaliwal (2015) revealed that propiconazole was discovered to be cytotoxic to human cancer cell line, exhibits an anticancer property, and is toxic to the liver. Furthermore, the Risk Assessment Committee (RAC) of the European Chemicals Agency (ECHA) has proposed that propiconazole be classified as toxic for reproduction category $1 \mathrm{~B}$, in accordance with the provisions of Regulation (EC) No $1272 / 2008$, due to the toxic effects on the endocrine organs and the contamination of groundwater (Arena et al., 2017).

Although there is a concern on costeffectiveness to produce a higher yield of rhamnolipid, Nalini and Parthasarathi (2018) suggested the application of solid-state fermentation, which was more efficient and cheaper in the production of biosurfactant compared to the conventional method by using submerged fermentation. Furthermore, they mentioned that rhamnolipid is a better alternative to chemical surfactants because of its low toxicity, greater biodegradability, environmentally friendly, and ability to reduce agrochemicals. Besides, rhamnolipid could also be applied directly to the diseased plant to control the fungal growth in vivo (Monnier et al., 2020).

Presumably, rhamnolipid incorporated into the PDA had not caused any significant changes in the $\mathrm{pH}$ values compared to the control (Figure 3). According to de Freitas Ferreira et al. (2019), rhamnolipid increased the antimicrobial activity in acidic conditions, and it can be classified as a $\mathrm{pH}$-dependent biosurfactant. This finding seems contradictory with the result in this

Table 3

Mean inhibition of Rigidoporus microporus (AM isolate) at different propiconazole concentrations in amended $P D A$

\begin{tabular}{ccccccc}
\hline Percentage inhibition of & \multicolumn{6}{c}{ Concentration of propiconazole (ppm) } \\
\cline { 2 - 6 } radial growth (\%) & 0 & 10 & 25 & 50 & 100 & 200 \\
\hline \multirow{2}{*}{ AM } & $0.00 \pm$ & $76.27 \pm$ & $100.00 \pm$ & $100.00 \pm$ & $100.00 \pm$ & $100.00 \pm$ \\
& $0.00^{\mathrm{a}}$ & $0.90^{\mathrm{b}}$ & $0.00^{\mathrm{c}}$ & $0.00^{\mathrm{c}}$ & $0.00^{\mathrm{c}}$ & $0.00^{\mathrm{c}}$ \\
\hline
\end{tabular}

Note. Data are means of three replicates \pm SE. Different letters within each column indicate significantly different values $(p \leq 0.05)$ according to Duncan's multiple range test (DMRT) 
study that showed the highest inhibition $(>70 \%)$ of $R$. microporus isolates at the $\mathrm{pH}$ 6.29 (neutral condition) compared to a low inhibition (\%) at a lower $\mathrm{pH}$ (more acidic condition). In the other study, Hadi et al. (2021) revealed that the higher $\mathrm{pH}$ of PDA after amended with soluble silicon did affect the growth of $R$. microporus (AM isolate), whereas no inhibition of $R$. microporus isolates was recorded in amended PDA without soluble silicon at higher $\mathrm{pH}$. This finding was supported by the other study that mentioned the increase in $\mathrm{pH}$ values after incorporating soluble silicon into PDA did not solely cause the inhibition of mycelial growth of Phytophthora cinnamomi as the comparison test by increasing the $\mathrm{pH}$ values of PDA by using potassium hydroxide $(\mathrm{KOH})$ had not given a significant reduction in the growth of $P$. cinnamomi mycelial (Kaiser et al., 2005). On the other hand, Prasetyo et al. (2009) mentioned that the growth of $R$. microporus in the rubber plantation was enhanced in the porous soil with neutral soil $\mathrm{pH}$ approximately between 6 to 7 . Thus, the $\mathrm{pH}$ values can be ruled out as the main cause of the $R$. microporus growth inhibition.

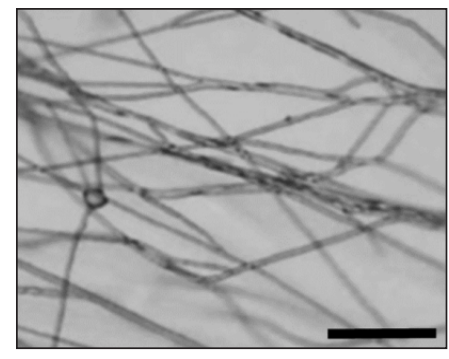

(a)

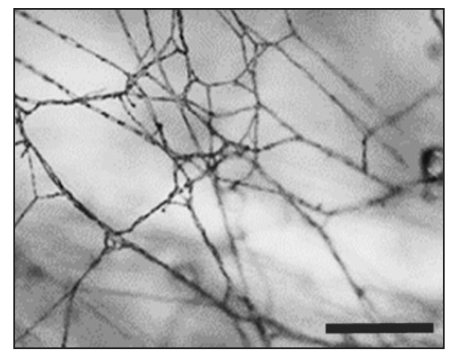

(b)
The observation of $R$. microporus mycelial under a light compound microscope revealed the morphological changes of the mycelial structure comparing the untreated mycelial of $R$. microporus with the treated mycelial in amended PDA with 10 ppm and $200 \mathrm{ppm}$ of rhamnolipid (Figure 5). The untreated mycelial were long, even, and the round hyphal with a smooth surface (Figure 5a). However, it was observed that the treated mycelial of $R$. microporus with rhamnolipid had shown sparse, asymmetric, curling, and twisting mycelium (Figure $5 \mathrm{~b}$ ); thinner and distorted newborn hyphae (Figure 5c). This result is similar to the scanning electron microscope observations of Borah et al. (2016), who found that the mycelial of Fusarium verticillioides FS7 was exhibited an irregular shape with an uneven surface, severely reduced thickness, and breakage after treated with rhamnolipid at the concentration of $200 \mathrm{mg} \mathrm{l}^{-1}$ in potato dextrose broth as compared to untreated mycelial. A fungus contains the vegetative structure known as mycelium that plays a crucial role in asexual reproduction and disease progression. As a result, any disruption to the mycelial integrity of a

Figure 5. Olympus CX41 light compound microscope images of (a) the untreated mycelial of Rigidoporus microporus (AM isolate); (b) mycelial treated with 10 ppm rhamnolipid; (c) mycelial treated with 200 ppm of rhamnolipid (scale bar: $200 \mu \mathrm{m}$; magnification at 10×) 
fungus may have a detrimental effect on the pathogenicity of the fungus.

In this study, the light compound microscope was used to assess the effect of rhamnolipid on the mycelia of $R$. microporus. The findings demonstrated that rhamnolipid, a biosurfactant generated by $P$. aeruginosa USM-AR2, could severely modify the morphology of fungal mycelia. It has previously been observed that rhamnolipid influences the mycelial structure of fungi (Borah et al., 2016; Yan et al., 2015). The damage could be caused by the rhamnolipid's surfactant activity, which causes the breakdown of the phospholipid bilayer of the cell membrane, resulting in the leakage of electrolytes, proteins, and DNA (Bharali et al., 2013; Yan et al., 2015). According to Sotirova et al. (2012) and Monnier et al. (2019), the ability of rhamnolipid to inhibit fungal mycelial growth was attributed to the degradation of the cell membrane. Based on these results, early predictions can be made where rhamnolipid could have an inhibitory effect on fungal growth in vitro, mostly fungicidal.

\section{CONCLUSION}

The results of the present investigation reveal that the rhamnolipid biosurfactant produced by the bacterial strain Pseudomonas aeruginosa USM-AR2 has strong antifungal activity against Rigidoporus microporus, which may offer the possibility of its application as an alternative fungicide. In addition, the production of rhamnolipid from recycled material, such as waste cooking oil, is expected to be more economical and environmentally friendly than a current commercial fungicide. However, the concentration at which complete suppression of a particular fungus occurs varies and must be determined in vitro before in vivo investigations are initiated. Therefore, pot and field trials are suggested to be carried out in the near future to confirm the efficacy of rhamnolipid against $R$. microporus in vivo.

\section{DECLARATION OF COMPETING INTEREST}

The authors declare that they have no known competing financial interests or personal relationships that could have appeared to influence the work reported in this paper.

\section{ACKNOWLEDGEMENTS}

The authors would like to thank the researchers from the Integrated Disease and Plant Management Unit of the Malaysian Rubber Board for kindly supplying the isolates of $R$. microporus as well as for technical support and help in the experiments. We also thank the Malaysian Rubber Board for the academic shcolarship. This research is funded by the Fundamental Research Grant Scheme: FRGS/1/2020/ WAB04/USM/02/2 from the Ministry of Higher Education Malaysia. Furthermore, rhamnolipid production was supported by Universiti Sains Malaysia through Research University Individual (RUI) Grant (1001/ PBIOLOGI/8011090). 


\section{REFERENCES}

AAT Bioquest Inc. (n.d.). Quest Graph ${ }^{\mathrm{TM}}$ EC50 calculator. https://www.aatbio.com/tools/ec50calculator

Andrew, B., Ahmad, K., Ismail, S. I., Ahmad, M. F., Ahmed, O. H., \& Yun, W. M. (2021). Disease prevalence and molecular characterisation of Rigidoporus microporus associated with white root rot disease of rubber tree (Hevea brasiliensis) in Malaysia. Journal of Rubber Research, 24(1), 175-186. https://doi.org/10.1007/s42464-02100083-x

Arena, M., Auteri, D., Barmaz, S., Bellisai, G., Brancato, A., Brocca, D., Bura, L., Byers, H., Chiusolo, A., Court Marques, D., Crivellente, F., De Lentdecker, C., De Maglie, M., Egsmose, M., Erdos, Z., Fait, G., Ferreira, L., Goumenou, M., Greco, L., ... Villamar-Bouza, L. (2017). Peer review of the pesticide risk assessment of the active substance propiconazole. EFSA Journal, 15(7), e04887. https://doi.org/10.2903/j. efsa.2017.4887

Atan, S. (2015). Integrated pest and disease management (IPDM): Our story [Unpublished document]. Malaysian Rubber Board.

Balamurugan, S. (2014). In vitro antifungal activity of Citrus aurantifolia linn plant extracts against phytopathogenic fungi Macrophomina phaseolina. International Letters of Natural Sciences, 13, 70-74. https://doi.org/10.18052/ www.scipress.com/ILNS.13.70

Bharali, P., Saikia, J. P., Ray, A., \& Konwar, B. K. (2013). Rhamnolipid (RL) from Pseudomonas aeruginosa OBP1: A novel chemotaxis and antibacterial agent. Colloids and Surfaces B: Biointerfaces, 103, 502-509. https://doi. org/10.1016/j.colsurfb.2012.10.064

Borah, S. N., Goswami, D., Sarma, H. K., Cameotra, S. S., \& Deka, S. (2016). Rhamnolipid biosurfactant against Fusarium verticillioides to control stalk and ear rot disease of maize. Frontiers in Microbiology, 7, 1505. https://doi.org/10.3389/ fmicb.2016.01505

Charles Oluwaseun, A., Julius Kola, O., Mishra, P., Ravinder Singh, J., Kumar Singh, A., Singh Cameotra, S., \& Oluwasesan Micheal, B. (2017). Characterization and optimization of a rhamnolipid from Pseudomonas aeruginosa C1501 with novel biosurfactant activities. Sustainable Chemistry and Pharmacy, 6, 26-36. https://doi.org/10.1016/j.scp.2017.07.001

Chen, C., Sun, N., Li, D., Long, S., Tang, X., Xiao, G., \& Wang, L. (2018). Optimization and characterization of biosurfactant production from kitchen waste oil using Pseudomonas aeruginosa. Environmental Science and Pollution Research, 25(15), 14934-14943. https://doi.org/10.1007/ s11356-018-1691-1

de Freitas Ferreira, J., Vieira, E. A., \& Nitschke, M. (2019). The antibacterial activity of rhamnolipid biosurfactant is $\mathrm{pH}$ dependent. Food Research International, 116, 737-744. https://doi. org/10.1016/j.foodres.2018.09.005

Deepika, K. V., Ramu Sridhar, P., \& Bramhachari, P. V. (2015). Characterization and antifungal properties of rhamnolipids produced by mangrove sediment bacterium Pseudomonas aeruginosa strain KVD-HM52. Biocatalysis and Agricultural Biotechnology, 4(4), 608-615. https://doi.org/10.1016/j.bcab.2015.09.009

Durgeshlal, C., Sahroj Khan, M., Prabhat, S. A., \& Aaditya Prasad, Y. (2019). Antifungal activity of three different ethanolic extract against isolates from diseased rice plant. Journal of Analytical Techniques and Research, 1(1), 47-63. https:// doi.org/10.26502/jatri.007

Farhana, A. H. K. F., Bahri, A. R. S., Thanh, T. A. V., \& Zakaria, L. (2017). Morphological features of Rigidoporus microporus isolated from infected Malaysian rubber clones. Malaysian Journal of Microscopy, 13(1), 17-23. 
Go, W. Z., Wong, M. Y., Tan, G. H., Chuah, A. L., Salmiah, U., Soni, O., Wong, W. Z., Chin, K. L., \& Chai, E. W. (2013). Occurence and characterisation of mycoflora in soil of different health conditions associated with white root rot disease in Malaysian rubber plantation. Journal of Rubber Research, 18(3), 159-170.

Goswami, D., Borah, S. N., Lahkar, J., Handique, P. J., \& Deka, S. (2015). Antifungal properties of rhamnolipid produced by Pseudomonas aeruginosa DS9 against Colletotrichum falcatum. Journal of Basic Microbiology, 55(11), 1265-1274. https://doi.org/10.1002/ jobm. 201500220

Hadi, S. M. H. S. A., Zakaria, L., Sidique, S. N. M., Mahyudin, M. M., \& Mohd, N. (2021). The potential of soluble silicon for managing white root disease in rubber (Hevea brasiliensis). Australian Journal of Crop Science, 15(10), 1346-1354. https://doi.org/10.21475/ ajcs.21.15.10.p3343

Hashim, I., \& Chew, B. H. (1997). Effects of integrating Trichoderma and fungicide on control of white root disease of Hevea rubber. Journal of Natural Rubber Research, 12(1), 43-57.

Ismail, H., \& Azaldin, M. Y. (1985). Interaction of sulphur with soil $\mathrm{pH}$ and root diseases of rubber. Journal Rubber Research Institute Malaysia, 33(2), 59-69.

Jayasuriya, K. E., \& Thennakoon, B. I. (2007). Biological control of Rigidoporus microporus, the cause of white root disease in rubber. Chiang Mai Journal of Science, 46(5), 850-866.

Jishma, P., Shad, K. S., Athulya, E., Sachidanandan, P., \& Radhakrishnan, E. (2021). Rhizospheric Pseudomonas spp. with plant growth promotion and antifungal properties against Sclerotium rolfsii mediated pathogenesis in Vigna unguiculata. Plant Biotechnology Reports, 15(4), 483-491. https://doi.org/10.1007/s11816021-00687-0
Kaiser, C., Merwe, R. Van Der, Bekker, T. F., \& Labuschagne, N. (2005). In-vitro inhibition of mycelial growth of several phytopathogenic fungi, including Phytophthora cinnamomi by soluble silicon. South African Avocado Growers' Association Yearbook, 28(1), 70-74.

Knebel, C., Neeb, J., Zahn, E., Schmidt, F., Carazo, A., Holas, O., Pavek, P., Püschel, G. P., Zanger, U. M., Süssmuth, R., Lampen, A., Marx-Stoelting, P., \& Braeuning, A. (2018). Unexpected effects of propiconazole, tebuconazole, and their mixture on the receptors CAR and PXR in human liver cells. Toxicological Sciences, 163(1), 170-181. https://doi.org/10.1093/toxsci/kfy026

Md Noh, N. A., Mohd Salleh, S., \& Yahya, A. R. M. (2014). Enhanced rhamnolipid production by Pseudomonas aeruginosa USM-AR2 via fedbatch cultivation based on maximum substrate uptake rate. Letters in Applied Microbiology, 58(6), 617-623. https://doi.org/10.1111/ lam. 12236

Monnier, N., Cordier, M., Dahi, A., Santoni, V., Guénin, S., Clément, C., Sarazin, C., Penaud, A., Dorey, S., Cordelier, S., \& Rippa, S. (2020). Semipurified rhamnolipid mixes protect Brassica napus against Leptosphaeria maculans early infections. Phytopathology, 110(4), 834-842. https://doi.org/10.1094/PHYTO-07-19-0275-R

Monnier, N., Furlan, A., Buchoux, S., Deleu, M., Dauchez, M., Rippa, S., \& Sarazin, C. (2019). Exploring the dual interaction of natural rhamnolipids with plant and fungal biomimetic plasma membranes through biophysical studies. International Journal of Molecular Sciences, 20(5), 1009. https://doi.org/10.3390/ ijms20051009

Nalini, S., \& Parthasarathi, R. (2018). Optimization of rhamnolipid biosurfactant production from Serratia rubidaea SNAU02 under solidstate fermentation and its biocontrol efficacy against Fusarium wilt of eggplant. Annals of 
Agrarian Science, 16(2), 108-115. https://doi. org/10.1016/j.aasci.2017.11.002

Ndlovu, T., Rautenbach, M., Khan, S., \& Khan, W. (2017). Variants of lipopeptides and glycolipids produced by Bacillus amyloliquefaciens and Pseudomonas aeruginosa cultured in different carbon substrates. AMB Express, 7, 109. https:// doi.org/10.1186/s13568-017-0367-4

Nicole, M. R., \& Benhamou, N. (1991). Ultrastructural localization of chitin in cell walls of Rigidoporus lignosus, the white-rot fungus of rubber tree roots. Physiological and Molecular Plant Pathology, 39(6), 415-431. https://doi.org/10.1016/08855765(91)90008-6

Noh, N. A., Salleh, S. M., Abdullah, A. A., \& Mohd, A. R. (2012). Fed-batch cultivation of Pseudomonas aeruginosa USM-AR2 producing rhamnolipid in bioreactor through pulse feeding strategy. International Proceedings of Chemical, Biological and Environmental Engineering, 40(34), 168-174.

Ogbebor, O. N., Adekunle, T. A., Eghafona, O. N., \& Ogboghodo, A. I. (2015). In vitro and in vivo botanical control of Rigidoporus microporus (sw.) overeem of para rubber in Nigeria. European Journal of Academic Essays, 2(3), 60-68.

Oghenekaro, A. O., Raffaello, T., Kovalchuk, A., \& Asiegbu, F. O. (2016). De novo transcriptomic assembly and profiling of Rigidoporus microporus during saprotrophic growth on rubber wood. BMC Genomics, 17(1), 234. https://doi.org/10.1186/s12864-016-2574-9

Prasetyo, J., Aeny, T. N., \& Suharjo, R. (2009). The corelations between white rot (Rigidoporus lignosus L.) incidence and soil characters of rubber ecosystem in Penumangan Baru, Lampung. Jurnal Hama dan Penyakit Tumbuhan Tropika, 9(2), 149-157.

Radzuan, M. N., Banat, I. M., \& Winterburn, J. (2017). Production and characterization of rhamnolipid using palm oil agricultural refinery waste. Bioresource Technology, 225, 99-105. https:// doi.org/10.1016/j.biortech.2016.11.052

Rodesuchit, A., Suchatgul, S., Klaewklong, B., \& Damnoi, S. (2012). Efficacy of fertilizers to control white root disease of rubber caused by Rigidoporus microporus at the early planting stages. Rubber Thai Journal, 72(3), 62-72.

Satapute, P. P., \& Kaliwal, B. B. (2015). In vitro toxicity screening of triazole fungicide propiconazole. International Journal of Recent Scientific Research, 6(9), 6525-6528.

Satchuthananthavale, V., \& Halangoda, L. (1971). Sulphur in the control of white root disease. Journal Rubber Research Institute Ceylon, 48, 82-91.

Sha, R., \& Meng, Q. (2016). Antifungal activity of rhamnolipids against dimorphic fungi. The Journal of General and Applied Microbiology, 62(5), 233-239. https://doi.org/10.2323/ jgam.2016.04.004

Shi, J., Chen, Y., Liu, X., \& Li, D. (2021). Rhamnolipid production from waste cooking oil using newly isolated halotolerant Pseudomonas aeruginosa M4. Journal of Cleaner Production, 278, 44-54. https://doi.org/10.1016/j.jclepro.2020.123879

Siddiqui, N., Middleton, C., Ribeiro, C., Atan, S., \& Di Cola, A. (2017). Gel-based proteomic study for differential expression of Hevea brasiliensis root proteins in response to infection by soil fungus Rigidoporus microporus. Acta Horticulturae, 1152(31), 229-234. https://doi.org/10.17660/ ActaHortic.2017.1152.31

Skidmore, A. M., \& Dickinson, C. H. (1976). Colony interactions and hyphal interference between Septoria nodorum and phylloplane fungi. Transactions of the British Mycological Society, 66(1), 57-64. https://doi.org/10.1016/s00071536(76)80092-7

Sotirova, A., Avramova, T., Stoitsova, S., Lazarkevich, I., Lubenets, V., Karpenko, E., \& Galabova, 
D. (2012). The importance of rhamnolipidbiosurfactant-induced changes in bacterial membrane lipids of Bacillus subtilis for the antimicrobial activity of thiosulfonates. Current Microbiology, 65(5), 534-541. https://doi. org/10.1007/s00284-012-0191-7

Soytong, K., \& Kaewchai, S. (2014). Biological control of white root of rubber trees using Chaetomium cupreum. International Journal of Agricultural Technology, 10(1), 93-103.

Vanavil, B., \& Seshagiri Rao, A. (2018). Dual substrate fermentation using palm oil and glucose for production of eco-friendly biosurfactants using P. aeruginosa NITT 6L. Indian Journal of Chemical Technology, 25(1), 101-105.

Wattanasilakorn, S., Sdoodee, S., Nualsri, C., Chuenchit, S., Meesawat, U., \& Sopharat, J.
(2017). Assessment of rubber clonal rootstocks for the tolerance of white root disease (Rigidoporus microporus) in Southern Thailand. Walailak Journal of Science and Technology, 14(7), 549-561.

Yan, F., Xu, S., Chen, Y., \& Zheng, X. (2014). Effect of rhamnolipids on Rhodotorula glutinis biocontrol of Alternaria alternata infection in cherry tomato fruit. Postharvest Biology and Technology, 97, 32-35. https://doi.org/10.1016/j. postharvbio.2014.05.017

Yan, F., Xu, S., Guo, J., Chen, Q., Meng, Q., \& Zheng, X. (2015). Biocontrol of post-harvest Alternaria alternata decay of cherry tomatoes with rhamnolipids and possible mechanisms of action. Journal of the Science of Food and Agriculture, 95(7), 1469-1474. https://doi. org/10.1002/jsfa.6845 
